\title{
Developing Primary Propulsion for the Ares I Crew Launch Vehicle and Ares V Cargo Launch Vehicle
}

\author{
Rick Burt, First Stage Element Manager \\ Tom Williams, Deputy First Stage Element Manager \\ Exploration Launch Projects Office \\ Marshall Space Flight Center \\ Huntsville, AL 35812
}

\begin{abstract}
In accordance with the U.S. Vision for Space Exploration, NASA has been tasked to send human beings to the moon, Mars, and beyond. ${ }^{1}$ The first stage of NASA's new Ares I crew launch vehicle (Figure 1), which will loft the Orion crew exploration vehicle into low-Earth orbit early next decade, will consist of a Space Shuttle-derived fivesegment Reusable Solid Rocket Booster (RSRB); a pair of similar RSRBs also will be used on the Ares V cargo launch vehicle's core stage propulsion system. This paper will discuss the basis for choosing this particular propulsion system; describe the activities the Exploration Launch Projects (ELP) Office is engaged in at present to develop the first stage; and offer a preview of future development activities related to the first Ares I integrated test flight, which is planned for 2009.
\end{abstract}

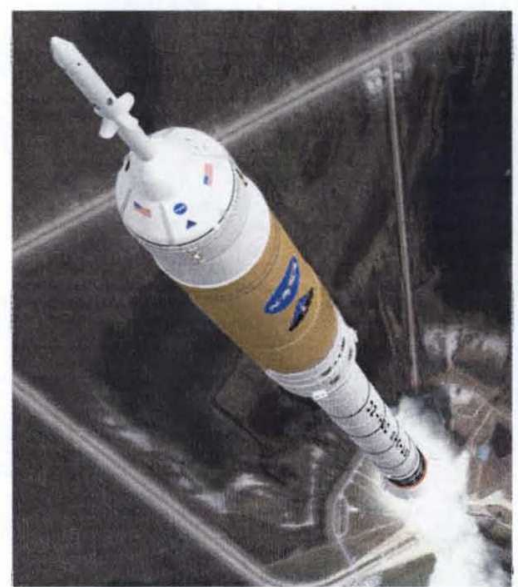

Figure 1. Ares I crew launch vehicle (NASA artist's concept).

As part of the U.S. Vision for Space Exploration, NASA commissioned the Exploration Systems Architecture Study (ESAS) to provide recommendations for fulfilling the U.S. goals of providing human transportation to the International Space Station, returning to the Moon, and traveling on to Mars. The ESAS committee recommended using a two-vehicle approach for these missions, separating crew from cargo for added safety. ${ }^{2}$ The Ares V cargo launch vehicle will go into orbit first, carrying the Lunar Surface Access Module in the Earth departure stage. Once the Ares V is in orbit, the Ares I crew launch vehicle will loft the Orion crew exploration vehicle into orbit to rendezvous with the Earth departure stage, which then ignites for the trans-lunar injection burn.

The original configuration for Ares I would have used a four-segment RSRB for the first stage and a Space Shuttle Main Engine (SSME) for the upper stage, while the Ares V would have used five SSMEs and two five-segment RSRBs for its core stage, followed by a Saturn-derived J-2X engine for the Earth departure stage. ${ }^{3}$ After further engineering and business studies showed it would be more expensive to redesign the SSME to ignite in the upper atmosphere, the Constellation Program accepted the ELP team's recommendation to use a derivative of the J-2 engine that powered the Saturn V third stage to the Moon. However, because the J-2X produced less thrust than the SSME, the first stage needed to be upgraded to provide additional thrust. This change proved valuable for two reasons: 
- The five-segment RSRB still uses Shuttle-derived hardware, allowing NASA to draw upon existing institutional knowledge and infrastructure.

- The five-segment RSRB is also part of the Ares V core stage, so ELP can apply test data, hardware, and lessons learned by experienced personnel from Ares I to Ares V development.

ELP will benefit from the Space Operations Mission Directorate's long experience operating the four-segment Shuttle booster, as the five-segment unit will use the same casing, propellant, thrust vectoring system, and a similar nozzle design. ELP will also gain valuable assistance from the Shuttle Program in developing the five-segment motor, as both directorates will share data from test and operational motor firings (Figure 2). More importantly, ELP's partner, ATK Launch Systems Group, has already performed static tests of a five-segment motor in 2003. The Space Shuttle Program flight support tests, which are performed with four-segment RSRBs, continue to provide valuable data collection opportunities for the Ares program. Data collected from these tests are shaping the final design of the Ares I launch vehicle, its hardware components, and its control subsystems. Building on proven propulsion systems has given designers a jumpstart on more advanced hardware testing. For example, RSRB Flight Support Motor (FSM) ground tests and Shuttle missions generate performance data that can be applied to the Ares I First Stage. Beginning with FSM-13, each RSRB ground test will be instrumented to collect data for Ares objectives. Since the Ares V will use two similar RSRBs, this information applies to that system, as well.

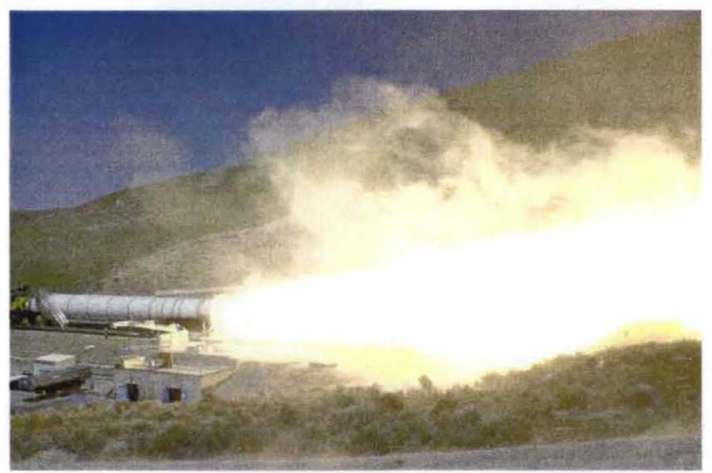

Figure 2. Four-segment RSRB static test firing, April 2006.

In addition to firing the motor, ELP is field testing critical RSRB subsystems, such as the launch recovery system and the separation pyrotechnics. The Ares I tests collected performance data on a pilot parachute (Figure 3), the first to be unfurled in a three-part recovery system NASA is developing for the rocket's first stage. Derived from the Shuttle's RSRB recovery system, the Ares system includes a pilot, drogue, and three main parachutes. The 11.5foot-diameter pilot chute was packed and mounted inside a 1,500-pound drop-test vehicle. Instruments and a recorder were mounted inside the test vehicle to capture data on the speed, weight on the parachute lines, and pressure during descent from an altitude of 10,000 feet.

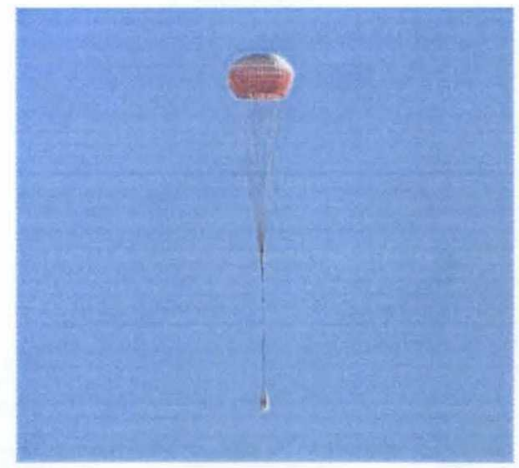

Figure 3. Parachute recovery system test, August 2006.

Additional tests will be conducted from higher altitudes to better simulate the velocity that the booster would experience after a typical ascent. The Ares I first stage booster Recovery System Development Test Program is a 2- 
year effort. Six additional pilot parachute tests are planned through 2008. Tests are also planned for the drogue and main parachutes.

The Ares I-1 ascent development flight, slated for April 2009, gives NASA its first opportunity to gather critical data about the flight dynamics of the integrated launch vehicle stack, understand how to control its roll during flight, and better characterize the severe stage separation environment that the upper stage engine will experience during future operational flights (Figure 4). NASA also will begin the process of modifying the launch infrastructure and fine-tuning ground and mission operational scenarios, as NASA transitions from the Shuttle to the Ares/Orion system.

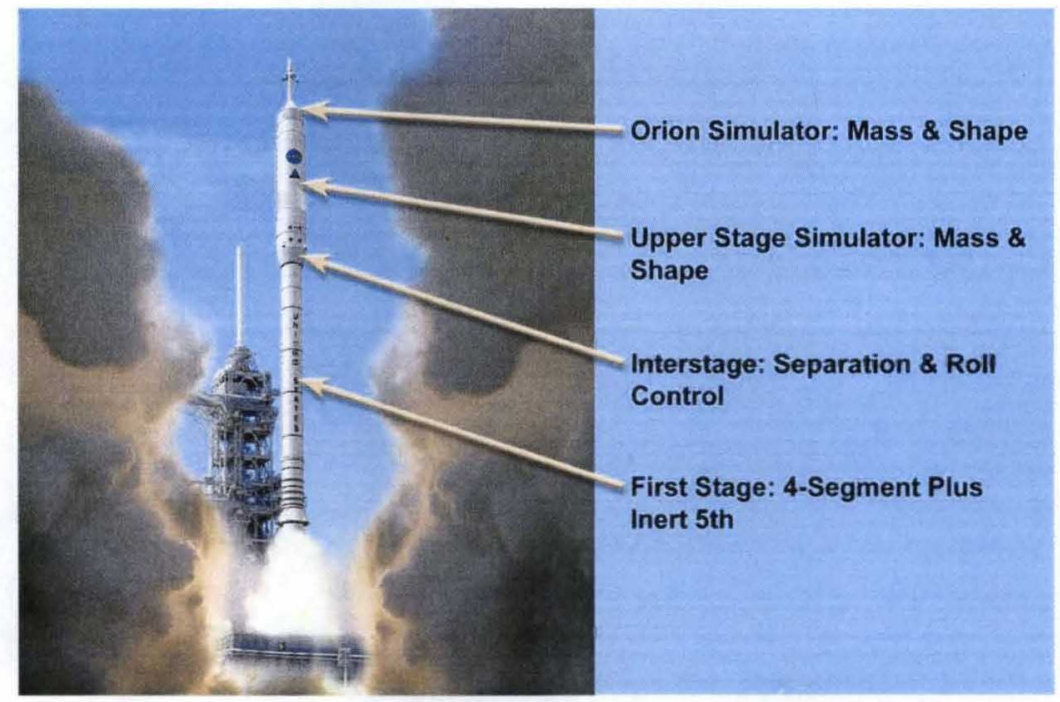

Figure 4. The Ares I flight test is planned for April 2009.

The Ares I-1 flight profile will closely mimic the flight conditions the launch vehicle experiences through Mach 4.5 and at an altitude of approximately 250,000 feet through the maximum dynamic pressure quotient (Max Q) of nearly 800 pounds per square foot. Mission elapsed time for first-stage burnout and upper stage separation will be closely matched (within a few seconds), at about 130 seconds into flight. The upper-stage simulator and the Orion Command Module/LAS simulator hardware will fall into the Atlantic and will not be retrieved. The First Stage booster will "fly" through a complete recovery sequence, and the hardware will be retrieved and analyzed. After recovery, the first stage hardware will be returned to the Kennedy Space Center for inspections and analysis. The data generated will provide information on which to base hardware and software design decisions, as well as to finetune operations processes and products.

It has been 30 years since the United States last designed and built a human-rated launch vehicle. NASA has marshaled unique resources from the government and private sectors to perform the technically and programmatically complex work of delivering astronauts to orbit early next decade, followed by heavy cargo late next decade. Our experiences with Saturn and the Shuttle have taught us the value of adhering to sound systems engineering, such as the "test as you fly" principle, while applying aerospace best practices and lessons learned. If we are to fly humans safely aboard a launch vehicle, we must employ a variety of methodologies to reduce the technical, schedule, and cost risks inherent in the complex business of space transportation. The Ares I First Stage team is using these methodologies to be "first off the ground" when Ares I takes flight in 2009.

\footnotetext{
References

${ }^{1}$ National Aeronautics and Space Administration. The Vision for Space Exploration. February 2004.

${ }^{2}$ National Aeronautics and Space Administration. NASA's Exploration Systems Architecture Study Final Report. NASA-TM-2005-214062. November 2005.

${ }^{3}$ Sumrall, John P., "A New Heavy-Lift Capability for Space Exploration: NASA's Ares V Cargo Launch Vehicle," International Astronautical Conference, 4 October 2006.
} 


\title{
Developing Primary Propulsion for the Ares I Crew Launch Vehicle and Ares V Cargo Launch Vehicle
}

\author{
Alex S. Priskos, Element Manager, Thomas J. Williams, Deputy Element Manager, and \\ Timothy G. Ezell, Chief Engineer \\ Exploration Launch Projects Office \\ First Stage Element Office, Marshall Space Flight Center, AL 35899
}

\begin{abstract}
In accordance with the U.S. Vision for Space Exploration, NASA has been tasked to send human beings to the moon, Mars, and beyond. ${ }^{1}$ The first stage of NASA's new Ares I crew launch vehicle (Figure 1), which will loft the Orion crew exploration vehicle into low-Earth orbit early next decade, will consist of a Space Shuttle-derived five-segment Reusable Solid Rocket Booster (RSRB); a pair of similar RSRBs also will be used on the Ares $V$ cargo launch vehicle's core stage propulsion system. This paper will discuss the basis for choosing this particular propulsion system; describe the activities the Exploration Launch Projects (ELP) Office is engaged in at present to develop the first stage; and offer a preview of future development activities related to the first Ares I integrated test flight, which is planned for 2009.
\end{abstract}

Figure 1. Ares I crew launch vehicle (NASA artist's concept).

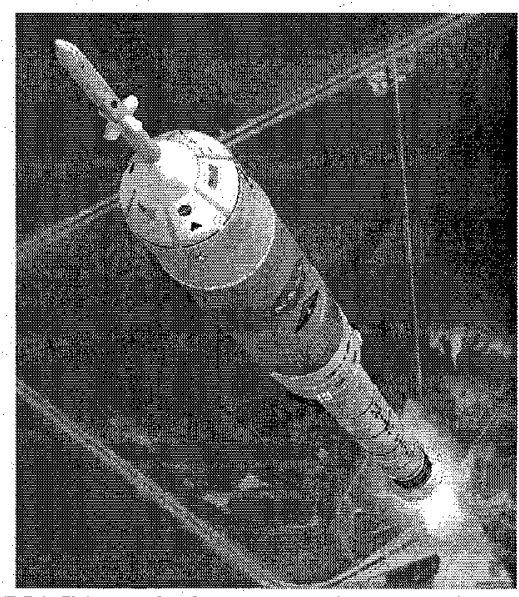

As part of the U.S. Vision for Space Exploration, NASA commissioned the Exploration Systems Architecture Study (ESAS) to provide recommendations for fulfilling the U.S. goals of providing human transportation to the International Space Station, returning to the Moon, and traveling on to Mars. The ESAS committee recommended using a two-vehicle approach for these missions, separating crew from cargo for added safety. ${ }^{2}$ The Ares $\mathrm{V}$ cargo launch vehicle will go into orbit first, carrying the Lunar Surface Access Module in the Earth departure stage. Once the Ares $V$ is in orbit, the Ares I crew launch vehicle will loft the Orion crew exploration vehicle into orbit to rendezvous with the Earth departure stage, which then ignites for the trans-lunar injection burn.

The original configuration for Ares I would have used a four-segment RSRB for the first stage and a Space Shuttle Main Engine (SSME) for the upper stage, while the Ares $V$ would have used five SSMEs and two five-segment RSRBs for its core stage, followed by a Saturnderived J-2X engine for the Earth departure stage. ${ }^{3}$ After further engineering and business studies showed it would be more expensive to redesign the SSME to ignite in the upper atmosphere, the Constellation Program accepted the ELP team's recommendation to use a 
derivative of the J-2 engine that powered the Saturn $V$ third stage to the Moon. However, because the J-2X produced less thrust than the SSME, the first stage needed to be upgraded to provide additional thrust. This change proved valuable for two reasons:

- The five-segment RSRB still uses Shuttle-derived hardware, allowing NASA to draw upon existing institutional knowledge and infrastructure.

- The five-segment RSRB is also part of the Ares V core stage, so ELP can apply test data, hardware, and lessons learned by experienced personnel from Ares I to Ares V development.

ELP will benefit from the Space Operations Mission Directorate's long experience operating the four-segment Shuttle booster, as the five-segment unit will use the same casing, propellant, thrust vectoring system, and a similar nozzle design. ELP will also gain valuable assistance from the Shuttle Program in developing the five-segment motor, as both directorates will share data from test and operational motor firings (Figure 2). More importantly, ELP's partner, ATK Launch Systems Group, has already performed static tests of a five-segment motor in 2003. The Space Shuttle Program flight support tests, which are performed with four-segment RSRBs, continue to provide valuable data collection opportunities for the Ares program. Data collected from these tests are shaping the final design of the Ares I launch vehicle, its hardware components, and its control subsystems. Building on proven propulsion systems has given designers a jumpstart on more advanced hardware testing. For example, RSRB Flight Support Motor (FSM) ground tests and Shuttle missions generate performance data that can be applied to the Ares I First Stage. Beginning with FSM-13, each RSRB ground test will be instrumented to collect data for Ares objectives. Since the Ares V will use two similar RSRBs, this information applies to that system, as well.

Figure 2. Four-segment RSRB static test firing, April 2006.

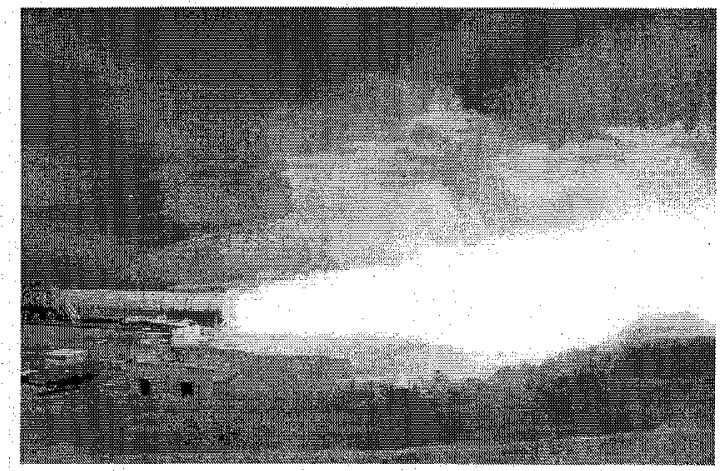

In addition to firing the motor, ELP is field testing critical RSRB subsystems, such as the launch recovery system and the separation pyrotechnics. The Ares I tests collected performance data on a pilot parachute (Figure 3), the first to be unfurled in a three-part recovery system NASA is developing for the rocket's first stage. Derived from the Shuttle's RSRB recovery system, the Ares system includes a pilot, drogue, and three main parachutes. The 11.5-foot-diameter pilot chute was packed and mounted inside a 1,500-pound drop-test vehicle. Instruments and a recorder were mounted inside the test vehicle to capture data on the speed, weight on the parachute lines, and pressure during descent from an altitude of 10,000 feet. 
Figure 3. Parachute recovery system test, August 2006.

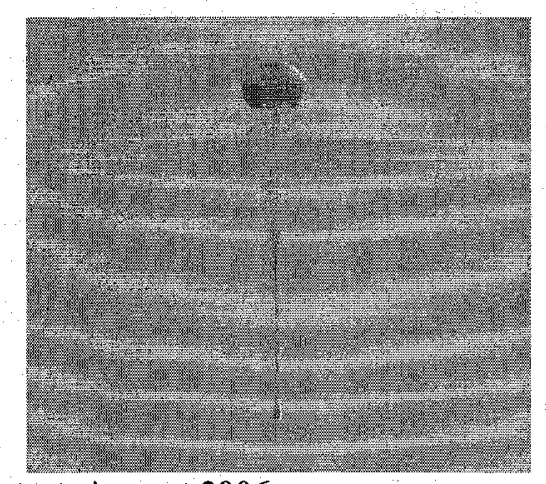

Additional tests will be conducted from higher altitudes to better simulate the velocity that the booster would experience after a typical ascent. The Ares I first stage booster Recovery System Development Test Program is a 2-year effort. Six additional pilot parachute tests are planned through 2008 . Tests are also planned for the drogue and main parachutes.

The Ares I-X ascent development flight, slated for April 2009, gives NASA its first opportunity to gather critical data about the flight dynamics of the integrated launch vehicle stack, understand how to control its roll during flight, and better characterize the severe stage separation environment that the upper stage engine will experience during future operational flights (Figure 4). NASA also will begin the process of modifying the launch infrastructure and fine-tuning ground and mission operational scenarios, as NASA transitions from the Shuttle to the Ares/Orion system.

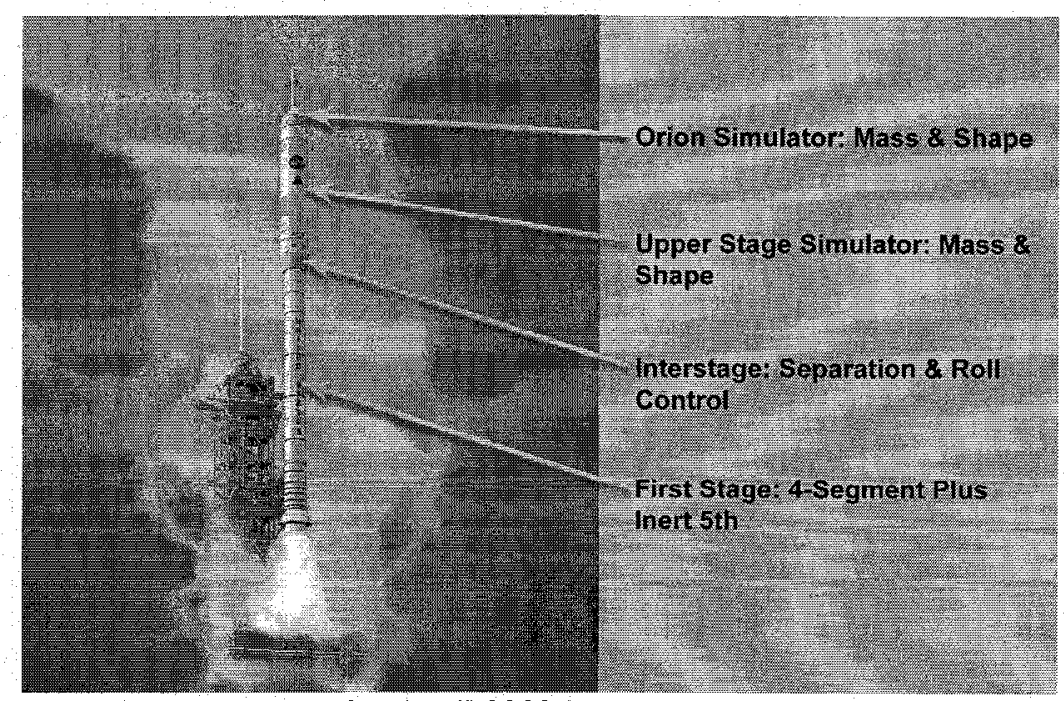

Figure 4. The Ares I flight test is planned for April 2009.

The Ares I-X flight profile will closely mimic the flight conditions the launch vehicle experiences through Mach 4.6 and at an altitude of approximately 150,000 feet through the maximum dynamic pressure quotient (Max Q) of nearly 800 pounds per square foot. Mission elapsed time for first-stage burnout and upper stage separation will be closely matched (within a few seconds), at about 130 seconds into flight. The upper-stage simulator and the Orion Command Module/LAS simulator hardware will fall into the Atlantic and will not be retrieved. The First Stage booster will "fly" through a complete recovery sequence, and the hardware will be retrieved and analyzed. After recovery, the first stage hardware will be returned to the Kennedy Space Center for inspections and analysis. The data 
generated will provide information on which to base hardware and software design decisions, as well as to fine-tune operations processes and products.

It has been 30 years since the United States last designed and built a human-rated launch vehicle. NASA has marshaled unique resources from the government and private sectors to perform the technically and programmatically complex work of delivering astronauts to orbit early next decade, followed by heavy cargo late next decade. Our experiences with Saturn and the Shuttle have taught us the value of adhering to sound systems engineering, such as the "test as you fly" principle, while applying aerospace best practices and lessons learned. If we are to fly humans safely aboard a launch vehicle, we must employ a variety of methodologies to reduce the technical, schedule, and cost risks inherent in the complex business of space transportation. The Ares I First Stage team is using these methodologies to be "first off the ground" when Ares I takes flight in 2009.

$\begin{array}{ll}A S A & =\text { Altitude Switch Assembly } \\ B D M & =\text { Booster Deceleration Motor } \\ B T M & =\text { Booster Tumble Motor } \\ C a L V & =\text { Cargo Launch Vehicle) } \\ C E V & =\text { Crew Exploration Vehicle } \\ C L V & =\text { Crew Launch Vehicle } \\ C M / L A S & =\text { Command Module/Launch Abort System } \\ & \text { (simulator) } \\ C P & =\text { Cylindrical Port } \\ D A C & =\text { Design Analysis Cycle } \\ D D T \& E & =\text { Design, Development, Test, and } \\ & \text { Evaluation } \\ D T V & =\text { Drop Test Vehicle } \\ E E L V & =\text { Evolved Expendable Launch Vehicle } \\ E L P & =\text { Exploration Launch Projects } \\ E S A S & =\text { Exploration Systems Architecture Study } \\ E T R & =\text { Eastern Test Range } \\ F I T O & =\text { Flight and Integrated Test Office } \\ F S M & =\text { Flight Support Motor } \\ F T I N U & =\text { Flight Test Inertial Navigation Unit } \\ F T S & =\text { Flight Termination System } \\ G N C & =\text { Guidance, Navigation, and Control } \\ J S C & =\text { Johnson Space Center }\end{array}$

Nomenclature

$\begin{array}{ll}\text { KSC } & =\text { Kennedy Space Center } \\ \text { LOC } & =\text { Loss of Crew } \\ \text { LOM } & =\text { Loss of Mission } \\ \text { LSC } & =\text { Linear Shaped Charge } \\ \text { Max } G & =\text { Maximum Gravity } \\ M a x Q & =\text { Maximum Dynamic Pressure } \\ \text { Mlbf-sec } & =\text { Million pounds of force per second } \\ M P S S & =\text { Main Parachute Support System } \\ M S F C & =\text { Marshall Space Flight Center } \\ m T & =\text { Metric Ton (Tonne) } \\ \text { NASA } & =\text { National Aeronautics and Space } \\ & \text { Administration } \\ P B A N & =\text { Polybutadiene Acrylonitrile } \\ P D R & =\text { Preliminary Design Review } \\ P S A & =\text { Production Simulation Article } \\ R S R B & =\text { Reusable Solid Rocket Booster } \\ S O M D & =\text { Space Operations Mission Directorate } \\ S R M & =\text { Solid Rocket Motor } \\ S S M E & =\text { Space Shuttle Main Engine } \\ S W & =\text { Space Wing } \\ T V C & =\text { Thrust Vector Control }\end{array}$

I. Introduction

7 HE United States has committed to a new program of human space exploration, which will extend well into the $121^{\text {st }}$ century. The Exploration Launch Projects Office at Marshall Space Flight Center (MSFC) in Huntsville, Alabama, is responsible for developing the propulsion systems for the first rockets to take humans beyond Earth orbit in over 40 years. Unlike the time-limited, cost-unlimited Apollo program, the Ares Launch Vehicles and the Orion Crew Exploration Vehicle (CEV) will be developed within tighter budget constraints and with long-term, lower-cost sustainability in mind.

\section{ESAS and Ares - Origins of the Architecture}

NASA has continued to amend its approach to this new initiative since President Bush's announcement of the Vision for Space Exploration (hereafter called "the Vision"). Originally designed for exploration purposes only, the CEV's mission was modified by Dr. Michael Griffin in 2005 when he became the new agency Administrator. ${ }^{4}$

As part of the new approach to the Vision, Dr. Griffin commissioned the Exploration Systems Architecture Study (ESAS) to provide recommendations for fulfilling the U.S. goals of providing human transportation to the International Space Station, returning to the Moon, and traveling on to Mars. The ESAS examined many different 
configurations to support the mission architecture, from vehicles using Space Shuttle-derived hardware to using upgraded versions of existing commercial Evolved Expendable Launch Vehicles (EELVs) (Tables 1 and 2). Among the considerations driving the architecture were payload to orbit, development costs, number of launches per mission, and safety factors such as loss of mission and loss of crew probabilities.

Table 1. Crew launch vehicle concepts investigated during ESAS. The highlighted column indicates the configuration that most closely resembles the current Ares I. The ESAS study originally recommended the 4Segment RSRB with 1 SSME.

\begin{tabular}{|c|c|c|c|c|c|c|c|}
\hline $\begin{array}{r}\text { Feet } \\
300 \\
200 \\
100\end{array}$ & 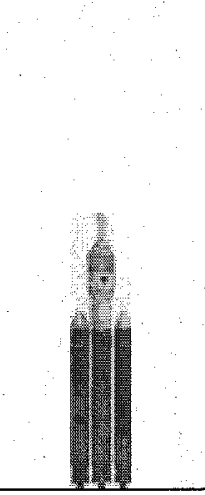 & (3) & (2) & 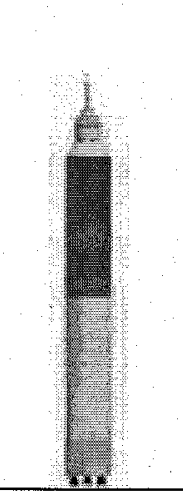 & $\frac{p^{2}}{4)}$ & 3 & $\begin{array}{l}3 \\
3 \\
3 \\
3 \\
3 \\
3 \\
3 \\
3 \\
3 \\
3\end{array}$ \\
\hline & $\begin{array}{c}\text { Human-Rated } \\
\text { Atlas V/New } \\
\text { US }\end{array}$ & $\begin{array}{c}\text { Human- } \\
\text { Rated } \\
\text { Delta IV/New } \\
\text { US }\end{array}$ & $\begin{array}{c}\text { Atlas } \\
\text { Phase 2 } \\
\text { (5.4-m Core) }\end{array}$ & $\begin{array}{l}\text { Atlas Phase } \\
\text { X (8-m Core) }\end{array}$ & $\begin{array}{c}4 \text { Segment } \\
\text { RSRB with } \\
1 \text { SSME }\end{array}$ & $\begin{array}{c}5 \text { Segment } \\
\text { RSRB with } \\
1 \mathrm{~J}-2 \mathrm{~S} \\
\end{array}$ & $\begin{array}{c}5 \text { Segment } \\
\text { RSRB with } \\
4 \text { LR-85 } \\
\end{array}$ \\
\hline $\begin{array}{c}\text { Payload } \\
\left(28.5^{\circ}\right)\end{array}$ & $30 \mathrm{mT}$ & $28 \mathrm{mT}$ & $26 \mathrm{mT}$ & $70 \mathrm{mT}$ & $25 \mathrm{mT}$ & $26 \mathrm{mT}$ & $27 \mathrm{mT}$ \\
\hline $\begin{array}{c}\text { Payload } \\
\left(51.6^{\circ}\right)\end{array}$ & $27 \mathrm{mT}$ & $23 \mathrm{mT}$ & $25 \mathrm{mT}$ & 67. $\mathrm{mT}$ & $23 \mathrm{mT}$ & $24 \mathrm{mT}$ & $25 \mathrm{mT}$ \\
\hline $\begin{array}{c}\text { LOM } \\
\text { (mean) }\end{array}$ & 1 in 149 & 1 in 172 & 1 in 134 & 1 in 79 & 1 in 460 & 1 in 433 & 1 in 182 \\
\hline $\begin{array}{c}\mathrm{LOC} \\
\text { (mean) }\end{array}$ & 1 in 957 & 1 in 1,100 & 1 in 939 & 1 in 614 & 1 in 2,021 & 1 in 1,918 & 1 in 1,429 \\
\hline
\end{tabular}

Table 2. Cargo Launch Vehicle concept comparisons. The highlighted column depicts the "1.5 launch" concept that most closely resembles the current launch architecture. As noted for Table 1, the ESAS originally recommended using a four-segment RSRB first stage and 1 SSME for the upper stage engine.

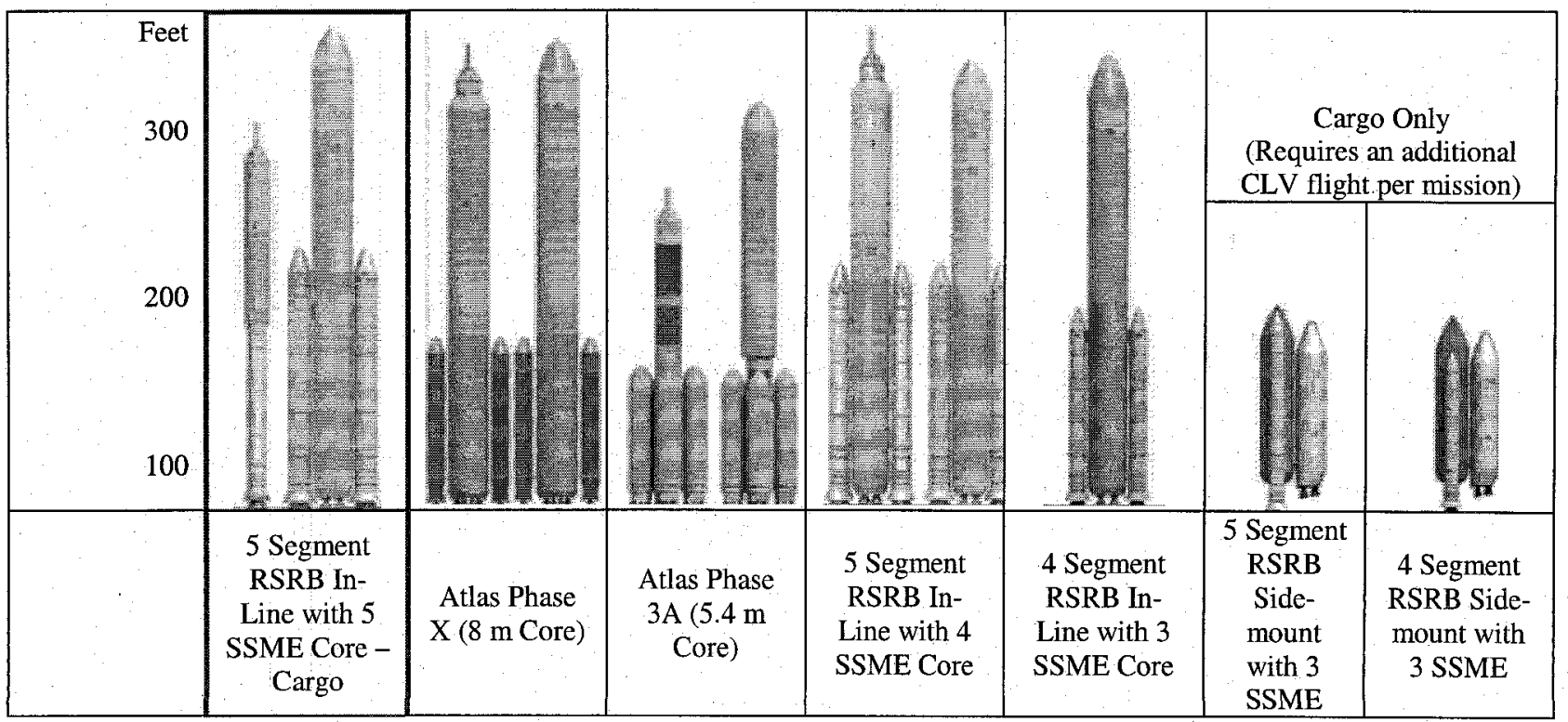




\begin{tabular}{|l|c|c|c|c|c|c|c|}
\hline $\begin{array}{l}\text { Payload } \\
\left(28.5^{\circ}\right)\end{array}$ & $\begin{array}{c}106 \mathrm{mT} \\
(125 \mathrm{mT} \\
\text { w/upper } \\
\text { stage) }\end{array}$ & $95 \mathrm{mT}$ & $94 \mathrm{mT}$ & $97 \mathrm{mT}$ & $74 \mathrm{mT}$ & $80 \mathrm{mT}$ & $67 \mathrm{mT}$ \\
\hline LOM (mean) & 1 in 124 & 1 in 71 & 1 in 88 & 1 in 133 & 1 in 176 & 1 in 172 & 1 in 173 \\
\hline LOC (mean) & 1 in 2,021 & 1 in 536 & 1 in 612 & 1 in 915 & 1 in 1,170 & N/A & N/A \\
\hline
\end{tabular}

At the end of this process, the ESAS committee recommended using a two-vehicle approach for these missions, separating crew from cargo for added safety. ${ }^{5}$ The Ares V cargo launch vehicle (CaLV) will go into orbit first, carrying the Lunar Surface Access Module in the Earth departure stage. Once the Ares V is in orbit, the Ares I crew launch vehicle will loft the Orion crew exploration vehicle into orbit to rendezvous with the Earth departure stage, which then ignites for the trans-lunar injection burn.

The original configuration for Ares I would have used a four-segment RSRB for the first stage and a Space Shuttle Main Engine (SSME) for the upper stage, while the Ares V would have used five SSMEs and two fivesegment RSRBs for its core stage, followed by a Saturn-derived J-2X engine for the Earth departure stage. ${ }^{6}$ However, further engineering and business studies showed it would be more expensive to redesign the SSME to ignite in the upper atmosphere. Thus, the Constellation Program accepted the ELP team's recommendation to use a derivative of the J-2 engine that powered the Saturn V third stage to the Moon. As a result of this decision, the first stage needed to be upgraded to provide additional thrust because the J-2X produced less thrust than the SSME. This change proved valuable for several reasons:

- The five-segment RSRB still uses Shuttle-derived hardware, allowing NASA to draw upon existing institutional knowledge and infrastructure, including an experienced workforce, known motor performance, existing tooling and manufacturing plants, and existing contractor relationships with ATK Launch Systems.

- The five-segment RSRB is also part of the Ares V core stage, so ELP can apply test data, hardware, and lessons learned by experienced personnel from Ares I to Ares V development.

ELP will benefit from the Space Operations Mission Directorate (SOMD's) long experience operating the foursegment Shuttle booster, as the five-segment unit will use the same casing, propellant, thrust vectoring system, and aft skirt, as well as a similar nozzle design. ELP also can gain valuable assistance from the Shuttle Program in developing the five-segment motor, as SOMD will share data from test and operational motor firings. More importantly, ELP's partner, ATK Launch Systems, has already performed static tests of a five-segment motor in 2003. The Space Shuttle Program flight support tests, which are performed with four-segment RSRBs, continue to provide valuable data collection opportunities for the Ares program. These tests also enable ATK and ELP to test Ares technologies on the Shuttle, such as a new, lightweight inside insulation.

Data collected from static and flight tests are shaping the final design of the Ares I launch vehicle, its hardware components, and its control subsystems. Building on proven propulsion systems has given designers a jumpstart on more advanced hardware testing. For example, RSRB Flight Support Motor (FSM) ground tests and Shuttle missions generate performance data that can be applied to the Ares I First Stage. Beginning with FSM-13, each RSRB ground test is being instrumented to collect data for Ares objectives. And, as stated earlier, this data will apply to the Ares $V$ because it will use two similar RSRBs. 


\section{Current Propulsion Developments}

\section{A. Structures}

Much of the RSRB consists of legacy hardware. However, because of Ares I's unique in-line configuration, the First Stage will require entirely new forward structures (Figure 5) and a modified systems tunnel. The new forward structures include the:

- Frustum - The frustum's primary function is to provide the physical transition from the smaller diameter of the First Stage and the larger diameter of the Upper Stage. Shortly after separation Booster Tumble Motors (BTM) located on the frustum ignite to begin the First Stage tumbling. The Frustum-Interstage assembly is jettisoned in a secondary separation at a separation plane located near the aft end of the frustum.

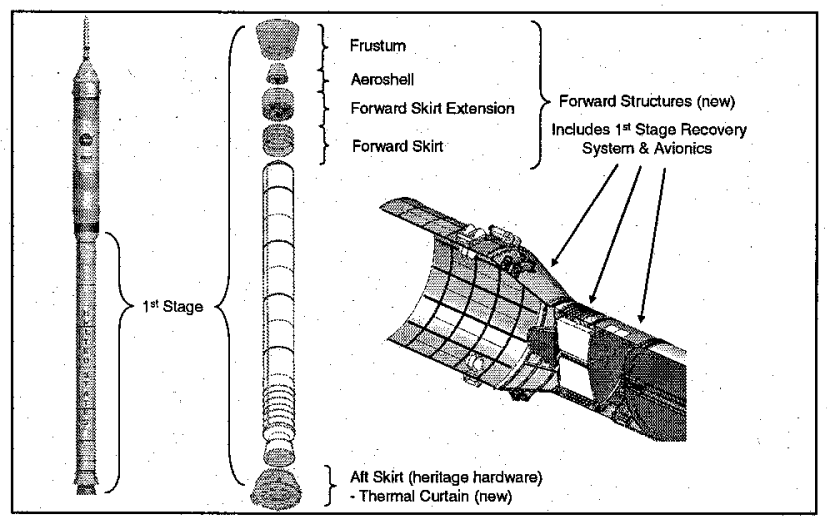

Figure 5. Expanded view of Ares I First Stage structures.

The centrifugal force as the First Stage begins to tumble will be enough to propel the Frustum-Interstage assembly away from the First Stage without re-contact. The Frustum and Interstage are not reused. Booster Deceleration Motors (BDMs) on the Interstage ignite to help propel the Frustum away from the First Stage without re-contact. The Frustum and Interstage are not reused. The Interstage structure is considered part of the Upper Stage element for Ares I, however, the First Stage element will manufacture the Interstage for the Ares I$\mathrm{X}$ test flight:

- Forward Skirt Extension - The forward skirt extension houses the Main Parachute Support System (MPSS) and main parachutes for First Stage recovery. In addition, the drogue and pilot parachutes sit atop the forward skirt extension and are protected by the heritage nose cap used on the current SRB.

- Forward Skirt - The forward skirt of the Ares I houses the First Stage avionics controls for ignition, thrust, and separation commands. For the Ares I-X test flight, the Forward Skirt may house the overall vehicle avionics, though this decision is still to be determined.

The new systems tunnel is a hollow protuberance that runs the length of the First Stage exterior and houses the avionics, control cabling, and Flight Termination System (FTS), which the Range Safety Officer will use to terminate vehicle thrust and break up the rocket if the vehicle steers off its intended trajectory toward populated areas.

Having passed the System Requirements Review, the First Stage Structural and Mechanical group is in the process of performing trade studies and iterative design analysis cycles (DACs) of the new structures. The net result of the second DAC was to move the aeroshell closer to the J-2X exhaust nozzle exit plane and to decrease the angle of the frustum. There is no change to the overall length of the vehicle. As the designs have matured, NASA is preparing to manufacture tooling to build the new forward structures by autumn of 2007 .

Another trade study under way for the First Stage will determine the location of the Flight Test Inertial Navigation Unit (FTINU), needed only for the Ares I-X flight test. While element-level avionics for the operational Ares I First Stage will be housed in the Forward Skirt, the "brains" of the overall vehicle, including Guidance, Navigation, and Control (GNC) will reside in the Instrument Unit located at the forward end of the Upper Stage. One of the primary aims of the flight test is to use Ares I control algorithms. If the FTINU is housed in the First Stage, those algorithms will no longer resemble the algorithms for the operational vehicle, effectively negating a primary flight test objective. This study is ongoing, and a final decision is expected soon.

Along with hardware preparation, the First Stage team will be refining its vehicle integration processes, from the manufacturing floor to launch operations at KSC. As components are assembled, they will be shipped from around the nation (structures from ATK Launch Systems in Utah, avionics and Thrust Vector Control system for the J-2X from Glenn Research Center in Ohio) to the Assembly and Refurbishment Facility at KSC. Once integrated, they will be moved to the Vehicle Assembly Building for vehicle stacking prior to launch. 


\section{B. Motor and Propellant Developments}

While the RSRB is one of the most reliable and best known of the Ares vehicle elements, it still requires redesign for its new operational requirements. The Constellation Program required a First Stage capable of providing a particular thrust trace over time, leading to a redesign of the propellant grain's shape and formulation, as well as a redesign of the motor nozzle. In addition to these new designs and formulations, ATK Launch Systems is developing new tooling to manufacture the new hardware.

One new occurrence that will aid in the progress of the First Stage is the funding of two additional development motors (DMs). These DMs will reduce technical risk; allow the team to pursue and evaluate parallel design options; and allow for a potential fault tolerance demonstration.

ATK Launch Systems and their subcontractors are building process simulation articles (PSAs) to help train their work forces in building the new hardware for Ares I. PSA development enables workers to build and streamline production processes before final production-quality hardware is built (Figure 8). Processes learned and honed in this environment will reduce cost and time later. Among the pieces undergoing this work are the mandrels, which are the molds around which propellant is
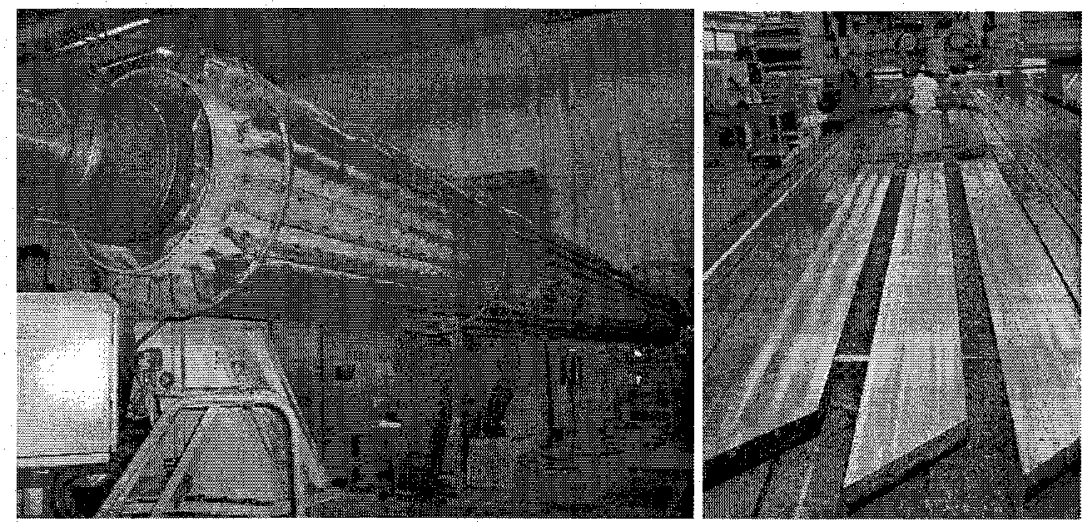

Figure 8. Mandrel process simulation articles are being fabricated. poured in the motor segments.

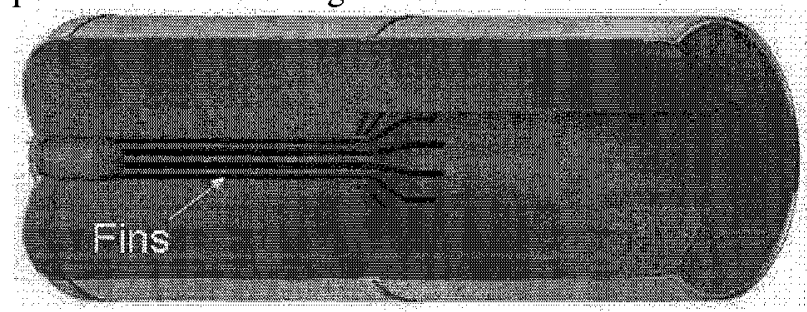

Figure 9. Cutaway view of RSRB forward segment.

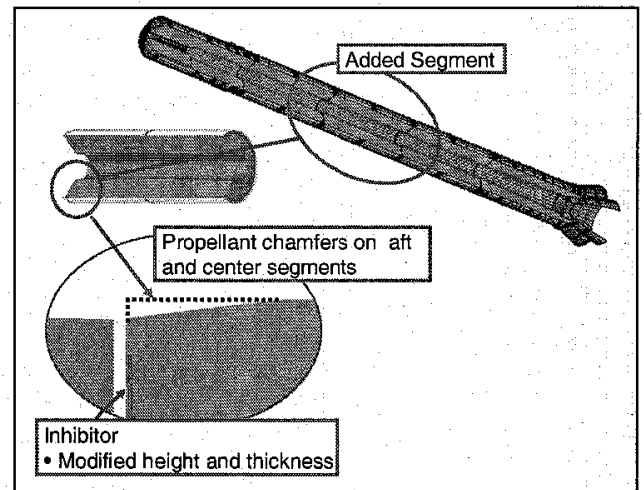

Figure 10. Cutaway views of segment chamfers and inhibitors
To use as much Shuttle-legacy hardware as possible, the exterior motor casings of the 5 -segment motor have been remained the same diameter. However, given the additional segment and the longer boost time, the interior shape of the polybutadiene acrylonitrile (PBAN) propellant will be modified to both provide additional thrust while maintaining the same combustion chamber pressures as the 4-segment booster.

To increase performance, the number of "fins" by the igniter at the forward end of the propellant chamber was increased from 11 to 12 , and the length of the "valleys" between those fins was reduced (Figure 9). This change increases the amount of surface area subject to combustion.

The second and fourth middle segments will include chamfers (bevels) and vertical inhibitors to ensure that the propellant burns evenly from the axis to the outer casing instead of burning (eroding) lengthwise down the bore of the propellant chamber (Figure 10).

Additionally, the nozzle needed to be widened because the motor is burning more propellant over a longer period of time. Widening the nozzle diameter ensures that more thrust can be generated and that internal pressure within the combustion chamber can remain within the tolerances specified for the Shuttle motor casings. 
The new thrust trace requirement also requires a different burn rate, which results in a slightly different propellant formulation. The new variant of PBAN will include additional iron oxide, producing slightly longer burn time than the 4-segment Shuttle motor (124.3 seconds instead of 123.5 seconds) and a much higher total impulse ( 366.7 million pounds of force per second (Mlbf-sec) instead of 297 Mlbf.-sec) (Figure 11). Supporting this new propellant formulation will be a new internal insulation, which will be lighter and more environmentally friendly (asbestos-free) than the current insulation used on the Shuttle's RSRBs.

The contractor partner developing the new insulation has performed structural and hot-fire tests with five-pound mixes, and has built full-scale production simulation articles to train their staff on manufacturing the new formulation. The new insulations will be rolled into a static test motor in late 2008 and into a five-segment motor sometime after that.

The team has already manufactured and tested five-inch-diameter cylindrical port $(\mathrm{CP})$ motors using the new propellant formulation. The $\mathrm{CP}$ motors will be tested to determine its mechanical properties, including tensile strength and ability to withstand stress.

\section{Avionics and Controls}

The team has made great progress on developing the First Stage avionics and control systems. The preliminary architecture has been defined, and the team has conducted a preliminary assessment of the Thrust Vector Control (TVC) system's performance requirements. The Shuttle-heritage TVC appears to meet the Ares I vehicle's requirements. Despite the vast difference in physical configurations, the Shuttle's performance requirements actually envelope those for Ares I.

Hardware-in-the-loop testing has begun at MSFC's System Integration Laboratory (SIL). The SIL will be used to conduct development and certification testing of the avionics system, its interfaces with control hardware like the Thrust Vector Control (TVC) system, and its ability to control the hardware. The aft skirt and TVC will be connected by fiber-optic cable to the SIL to verify interfaces and perform fault tolerance testing.

Additionally, the SIL will be instrumental in conducting testing of "green" working fluids for the TVC, such as helium, to replace the environmentally unfriendly hypergolic propellants currently powering the turbines for the pressurization pumps.

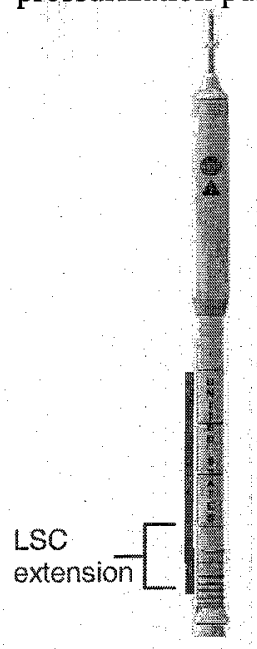

Figure 12. Linear Shaped Charge Extension location.

\section{Flight Termination System}

In the years since the Space Shuttle first launched, the U.S. Air Force's $45^{\text {th }}$ Space Wing (SW), which controls range safety for the Eastern Test Range (ETR), has modified its range safety requirements to better protect populated areas. In the event of a flight termination, the aft segment of the RSRB would cause considerable damage if it were to land intact.

The vehicle's First Stage includes an FTS. The Ares I-X flight test vehicle is equipped with a Linear Shaped Charge (LSC) that extends along three of the four solid rocket motor (SRM) segments of the Ares I-X FTV (Figure 12),

The $45^{\text {th }} \mathrm{SW}$ has recommended that the LSC be extended to all four segments for the Ares I-X flight and all five segments of the Ares I to meet their requirements. Based on a study conducted by the Flight and Integrated Test Office (FITO), the First Stage team decided to extend the LSC to meet the Air Force requirement, which will increase the safety of the new vehicles. which provides the force to crack the cases of the three SRM segments. 


\section{E. Pyro Shock Testing}

As the First Stage separation events are executed, the Upper Stage hardware will be subjected to a high strain wave event, as a pyrotechnic linear shaped charge (LSC) initiates the stage separation. The acoustic effects of the strain rate or "shock" event can damage vibration-sensitive equipment like avionics or reaction control thrusters; therefore, the First Stage team is conducting pyro shock testing to characterize the shock loads these systems are likely to experience at separation. The tests are still in the development phase. Among the items the pyro team will need to balance are: joint thickness, effective pyrotechnic mass per foot, and joint load-bearing capabilities. Once testing is completed, the data will be passed on to all affected subsystems to ensure that the shock loads are accounted for in their designs.

\section{F. Parachute Testing}

NASA is conducting design development tests for the Ares I parachute recovery system. The system includes three different parachutes: pilot, drogue, and three main parachutes. At approximately 130 seconds after launch, the First Stage separates from the Upper Stage an altitude of 195,000 feet and free-falls, reentering the atmosphere. At approximately 15,000 feet, the booster's nose cap is jettisoned, releasing the pilot parachute and beginning the recovery sequence. The small pilot parachute deploys the larger drogue parachute, which is used to stabilize the booster into a vertical (tail-down) position and to slow its descent. Upon completion of this event, the drogue parachute is cut away and pulls out a cluster of three main parachutes, each 150 feet in diameter. The main parachutes continue to slow the booster for a safe splashdown (Figure 13). ${ }^{7}$

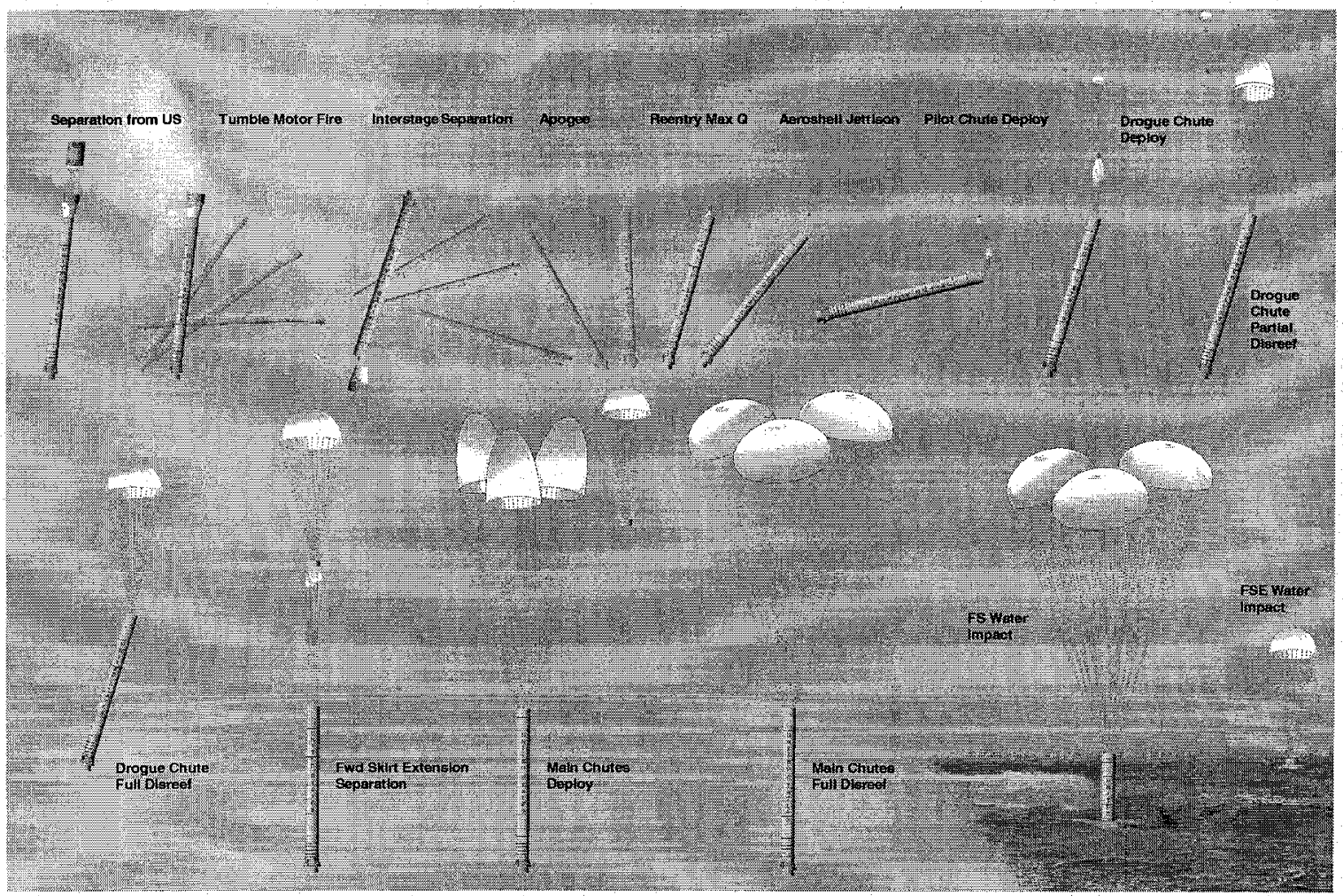

\section{Figure 13. First Stage recovery sequence.}

The Ares I pilot, drogue, and main parachutes are larger and stronger than the Shuttle's parachutes because the Ares I First Stage is much heavier, and reenters from a higher altitude with a much higher speed and mass. The tests are conducted incrementally, using increasingly larger loads for each test. The loads are controlled by the weight of the Drop Test Vehicles (DTVs) (Figure 14), the altitude from which they are dropped (Figure 15), and the amount of free-fall time before the test parachute is opened. The pilot and drogue chutes are opened using altitude switch assemblies (ASAs) to initiate pyrotechnic-powered cutters. When the drogue ASA closes, the main chute is set to open after a 20 -second time delay. 


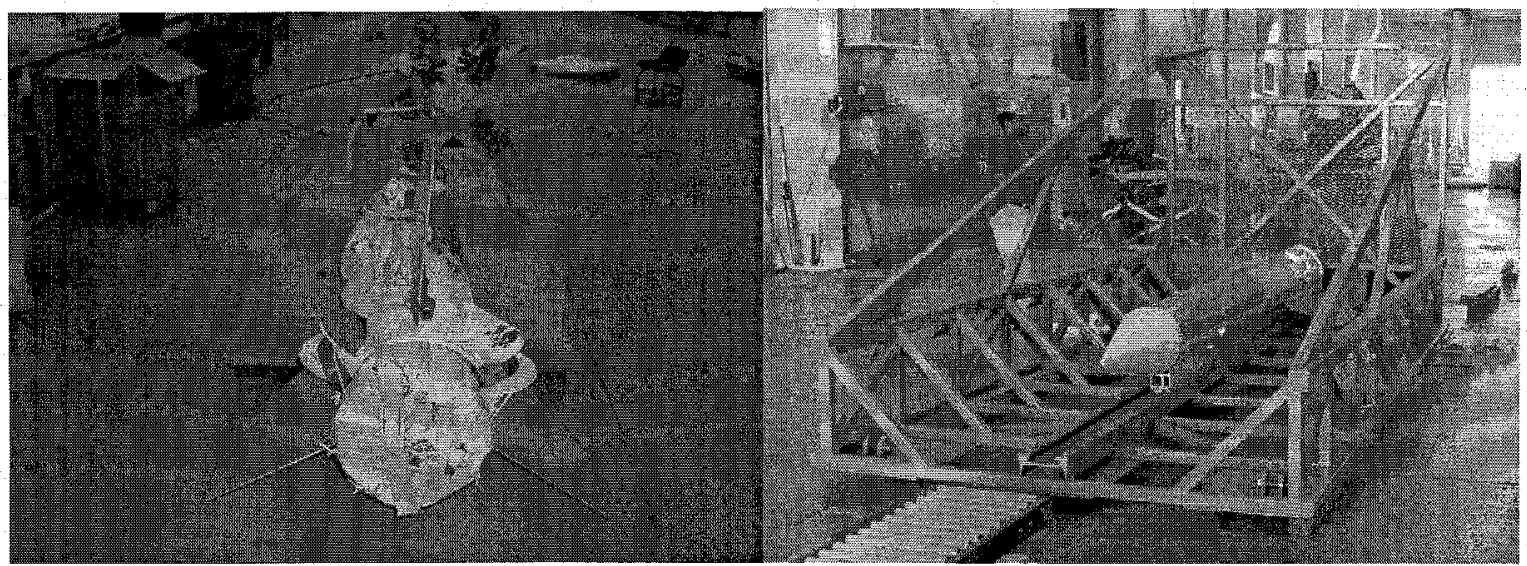

Figure 14. Aft view of the DTV parachute pack (left) and forward view of DTV in cradle (right) prior to aircraft loading.

The objective of the drop test program is to validate the final design of the parachutes. Actual qualification testing of the parachutes, the deployment sequence, and the entire recovery system will occur during the first few flights of Ares I. Although the early Ares I-X demonstration flight will not match the operational Ares I vehicle's flight characteristics related to reentry weight and speed, it will be used to provide a functional test of the entire recovery system in a flight environment.

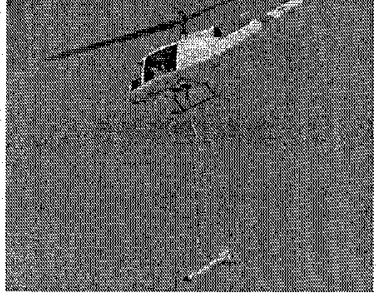

Figure 15. Parachute Drop Test Vehicle (DTV) prior to release.

While the initial two pilot parachute tests were successful, the third test conducted at the Yuma Proving Grounds in January 2007 failed. The DTV was in free fall longer than planned, which created a much larger load when the parachute opened. The Kevlar straps that attach the pilot parachute to the DTV broke just after pilot parachute opened due to this overload condition and the DTV fell to the ground without parachute braking. The First Stage project and engineering team at the Marshall Space Flight Center along with their contractor team have evaluated the video and recovered hardware. They have completed a failure investigation to determine the source of the failure and recommended corrective actions.

\section{G. Ares I-X Flight Test}

The Ares I-X ascent development flight, slated for April 2009, gives NASA its first opportunity to gather critical data about the flight dynamics of the integrated launch vehicle stack, understand how to control its roll during flight, and better characterize the severe stage separation environment that the upper stage engine will experience during future operational flights (Figure 6). NASA also will begin the process of modifying the launch infrastructure and fine-tuning ground and mission operational scenarios, as NASA transitions from the Shuttle to the Ares/Orion system. 


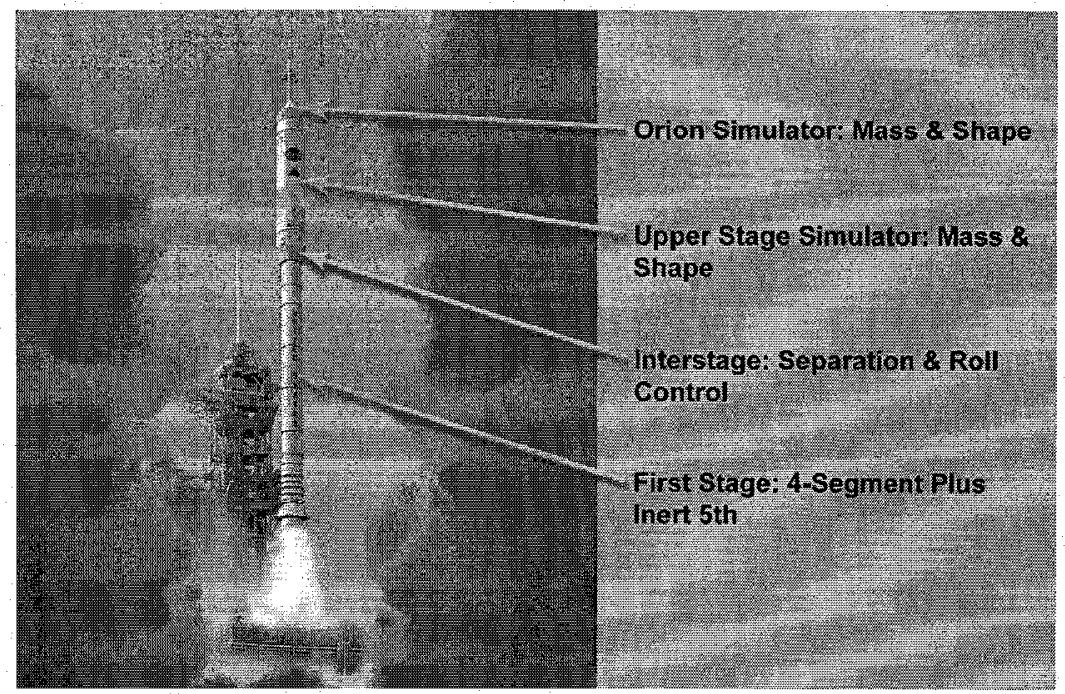

Figure 16. The Ares I flight test is planned for April 2009.

The Ares I-X flight profile will closely mimic the flight conditions the launch vehicle experiences through Mach 4.6 and at an altitude of approximately 150,000 feet through the maximum dynamic pressure quotient (Max Q) of nearly 800 pounds per square foot. Mission elapsed time for first-stage burnout and upper stage separation will be closely matched (within a few seconds), at about 130 seconds into flight. The upper-stage simulator and the Orion Command Module/LAS simulator hardware will fall into the Atlantic and will not be retrieved. The First Stage booster will "fly" through a complete recovery sequence, and the hardware will be retrieved and analyzed. After recovery, the first stage hardware will be returned to the Kennedy Space Center for inspections and analysis. The data generated will provide information on which to base hardware and software design decisions, as well as to fine-tune operations processes and products.

\section{Forward Work}

The Ares I First Stage team anticipates progress on a variety of fronts, including parachute testing, pyrotechnic shock testing, avionics and control interfaces, and the Ares I-X preliminary design review (PDR).

Design development testing for the parachute systems began in August 2006, starting with the pilot chute. Three tests of the pilot chute have been conducted so far, with the remaining two tests planned for the last week in July and one for late summer 2007. The initial tests of the drogue and main parachutes are scheduled to start in late 2007 and will finish in early 2009.

The avionics and control interfaces for the Ares I vehicle will be finalized by May 25 .

The First Stage team will conduct a series of major design reviews (MDRs) for each of the sub-elements over the next year to prepare for the Ares I-X test flight. These reviews will determine if each of the sub-element designs meet the overall vehicle requirements.

Pyro shock development tests will be performed on the heritage nosecap pressure cartridge in early June. These tests will determine if pyro loads adversely affect vehicle avionics and the thruster pressure cartridge.

The First Stage team is participating in a vehicle-level PDR for the Ares I-X test flight at Langley Research Center (LaRC) during the first week of May. The results of that review will determine NASA's readiness to complete the design of the flight test vehicle, scheduled for April 2009.

\section{Conclusion}

It has been 30 years since the United States last designed and built a human-rated launch vehicle. NASA has marshaled unique resources from the government and private sectors to perform the technically and programmatically complex work of delivering astronauts to orbit early next decade, followed by heavy cargo late next decade. Our experiences with Saturn and the Shuttle have taught us the value of adhering to sound systems engineering, such as the "test as you fly" principle, while applying aerospace best practices and lessons learned. If we are to fly humans safely aboard a launch vehicle, we must employ a variety of methodologies to reduce the technical, schedule, and cost risks inherent in the complex business of space transportation. The Ares I First Stage team is using these methodologies to be "first off the ground" when Ares I takes flight in 2009. The Ares I First 
Stage, based upon a robust, dependable design proven in the Space Shuttle Program, is one of the critical elements in sending humans to the Moon, Mars, and beyond. This productive heritage will ensure that NASA's new exploration vehicles remain cost effective throughout the next generation of space transportation.

\section{Acknowledgments}

The authors wish to thank Bart Leahy, Technical Writer with Schafer Corporation, for assistance in preparing this paper.

\section{References}

1 National Aeronautics and Space Administration. The Vision for Space Exploration. February 2004. http://www.nasa.gov/mission_pages/exploration/mmb/why_moon.html [cited 11 April 2007].

${ }^{2}$ National Aeronautics and Space Administration. "NASA's Exploration Systems Architecture Study Final Report." NASA-TM2005-214062. November 2005, p. 45.

${ }^{3}$ Sumrall, John P., "A New Heavy-Lift Capability for Space Exploration: NASA's Ares V Cargo Launch Vehicle," International Astronautical Conference, 4 October 2006.

${ }^{4}$ National Aeronautiç and Space Administration. NASA's Exploration Systems Architecture Study Final Report. NASA-TM2005-214062. November 2005, p. 1.

${ }^{5}$ Ibid.

${ }^{6}$ Sumrall, John P., "A New Heavy-Lift Capability for Space Exploration: NASA's Ares V Cargo Launch Vehicle," International Astronautical Conference, 4 October 2006.

${ }^{7}$ Bechtel, Sheri. "NASA Engineers Complete Series of Parachute Recovery System Tests for Ares First Stage." Marshall Star. 7 September 2006, p. 1. 
National Aeronautics and Space Administration

Exploration Launch Projects

Developing Primary Propulsion for the Ares I Crew Launch Vehicle and Ares V Cargo Launch Vehicle

Alex S. Priskos Manager

Thomas L. Williams

Deputy Manager

Timothy G. Ezell Chief Engineer

Ares I First Stage Office

AIAA Joint Propulsion Conference July 2007 


\section{Agenda}

- Overview and history of the Ares

Launch Vehicles

- Progress on current propulsion elements

- Forward work 


\section{Overview of the Exploration Launch Projects Architecture}

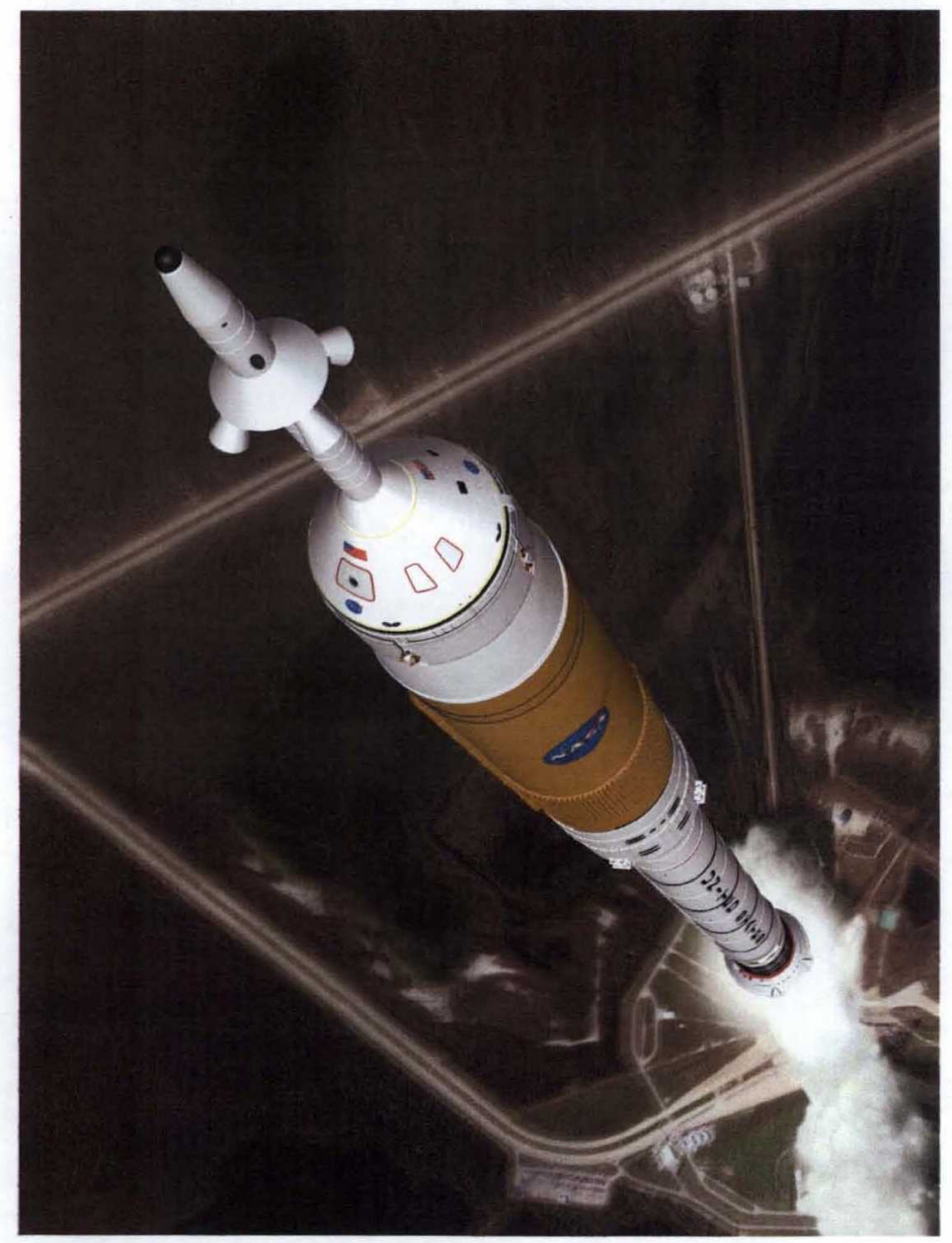

- Carries Crew Exploration Vehicle (CEV) to orbit to rendezvous with International Space Station or Ares V

- Ares I propulsion:

First Stage

- 5-segment Reusable Solid Rocket Booster (RSRB) Upper Stage

- J-2X 


\section{Exploration Launch Projects Architecture, Continued}

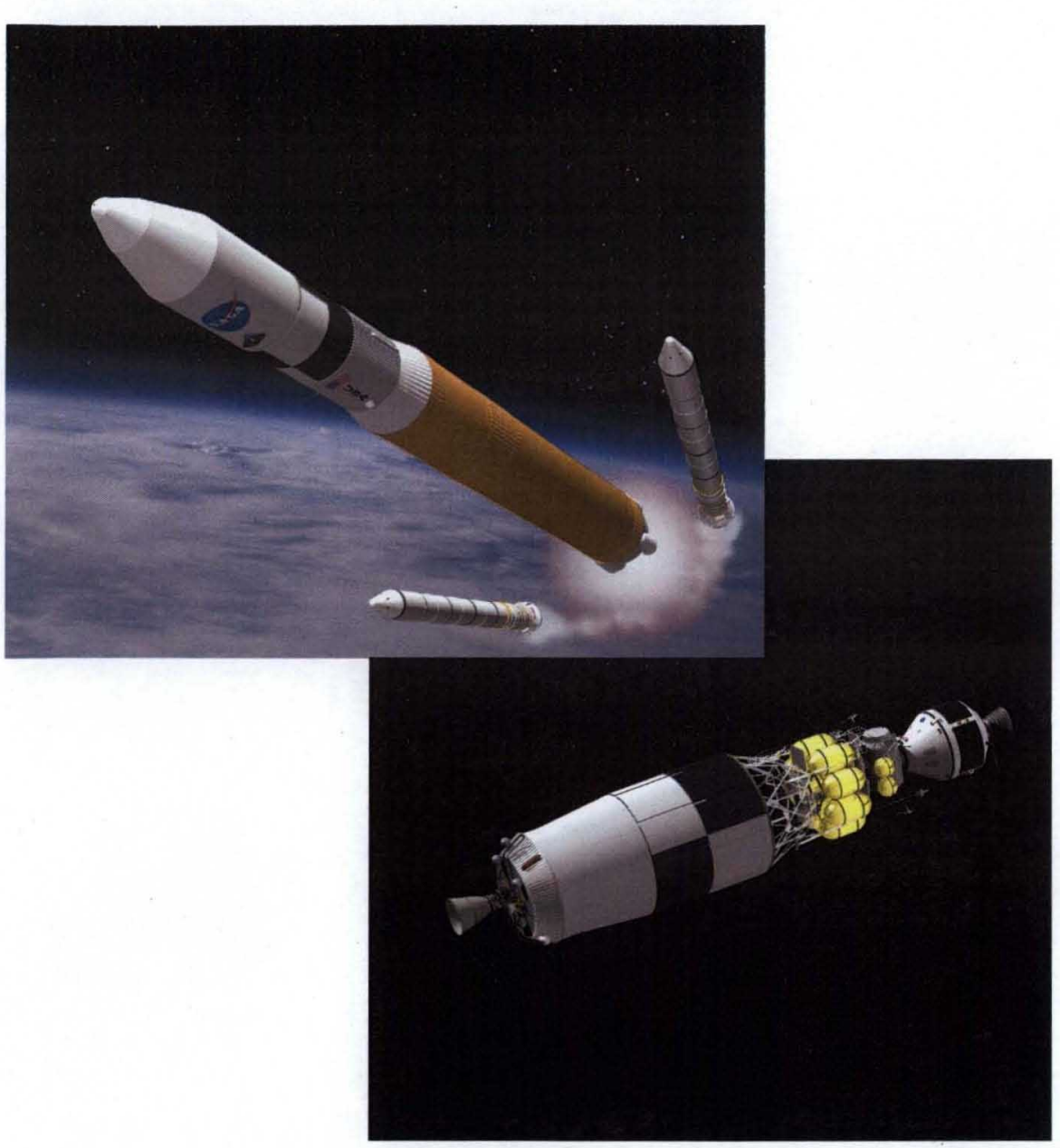

- Ares V carries cargo to ISS or Lunar Surface Access Module (LSAM) and Earth Departure Stage to orbit

- Ares V Propulsion:

Core Stage

- 2 RSRBs

- 5 RS-68

- 33-foot (10 meter) diameter Earth Departure Stage

- J-2X for orbit circularization and Trans-lunar injection (TLI) burn

- Common hardware and procedures with Ares I to reduce development and operations costs 


\section{Exploration Systems Architecture Study (ESAS)}

- Commissioned by Dr. Griffin in 2005

- Evaluated vehicles for ability to fulfill the Vision

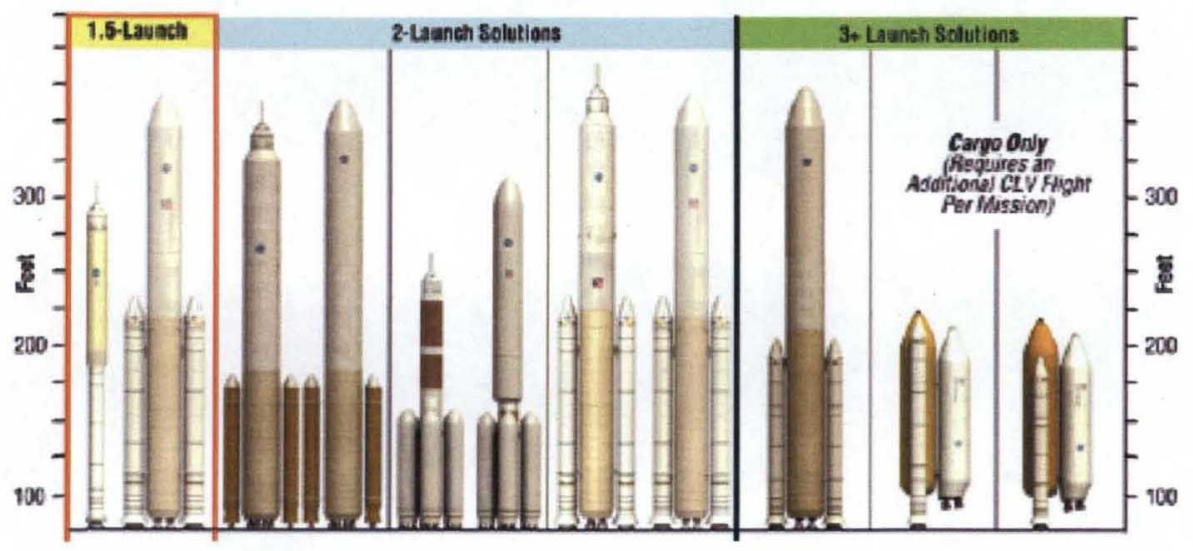

- Recommended two-vehicle approach based on Shuttle and Saturn elements

- Proven hardware

- Leverage institutional knowledge and infrastructure

- Experienced workforce

- CLV First Stage changed from 4-segment SRB to 5-segment SRB after Space Shuttle Main Engine (SSME) replaced by J$2 X$ 


\section{First Stage Participants}

Spacecraft Adapter

J-2X Upper Stage Engine
Launch Abort System

Orion Crew Exploration Vehicle (Crew Module / Service Module)

Instrument Unit

Upper Stage

Interstage

First Stage

(5-Segment RSRB)
- The Exploration Launch Projects Office

Managing design, development, and manufacturing of Ares

- The First Stage Element Office: Managing, designing, developing, and manufacturing the First Stage booster

- ATK Launch Systems First Stage prime contractor

- Kennedy Space Center (KSC) Ground Operations Performing First Stage vehicle integration and launch services 


\section{Ares I First Stage Progress}

- Structures

- Motor and propellant

- Avionics and controls

- Flight Termination System (FTS)

- Pyro shock testing

- Parachute testing

- Ares I-X flight test 


\section{Structures}

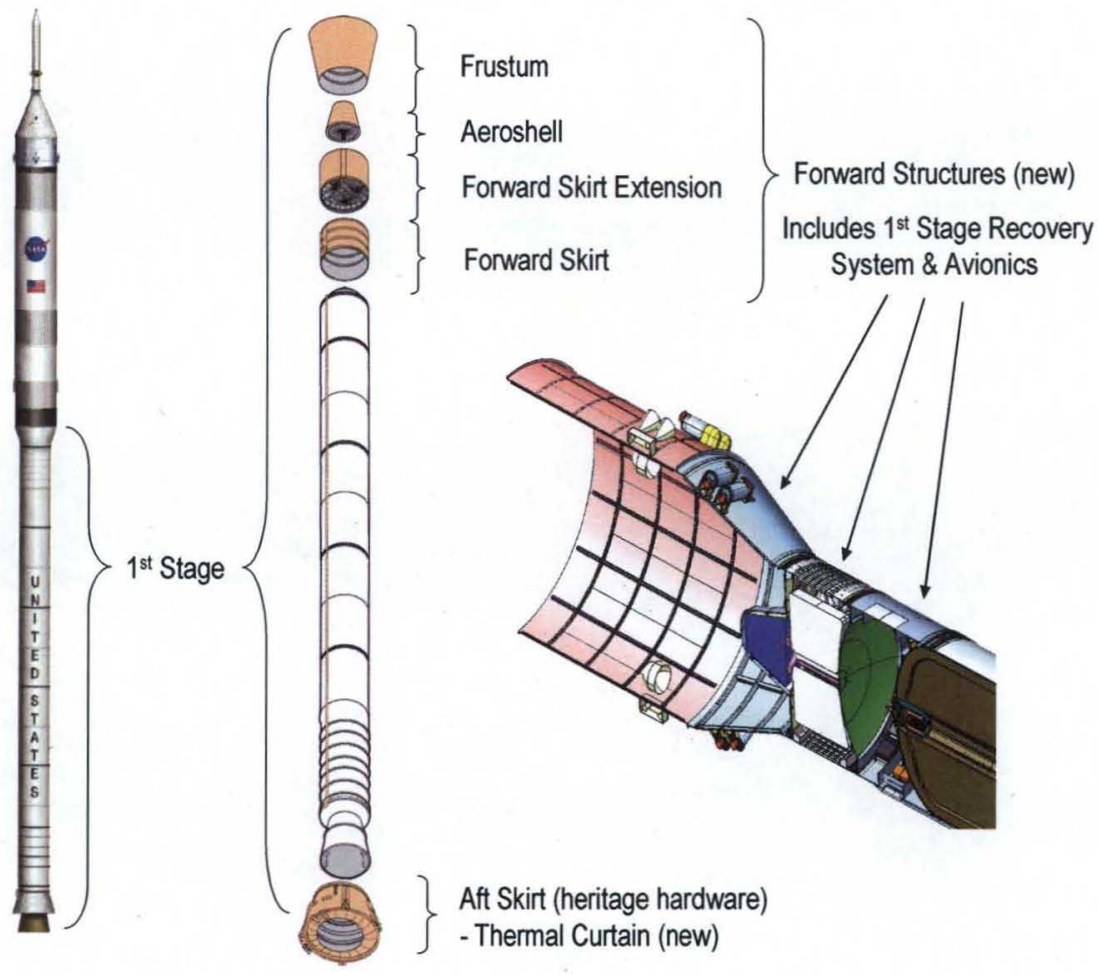

New forward structures

- Frustum - Physical transition from First to Upper Stage

- Forward Skirt Extension Houses Main Parachute Support System (MPSS)

- Forward Skirt - Houses First Stage avionics

- Material trade study complete

Modified structures

- Systems Tunnel - Extended to accommodate extended FTS 


\section{Motor and Propellant}
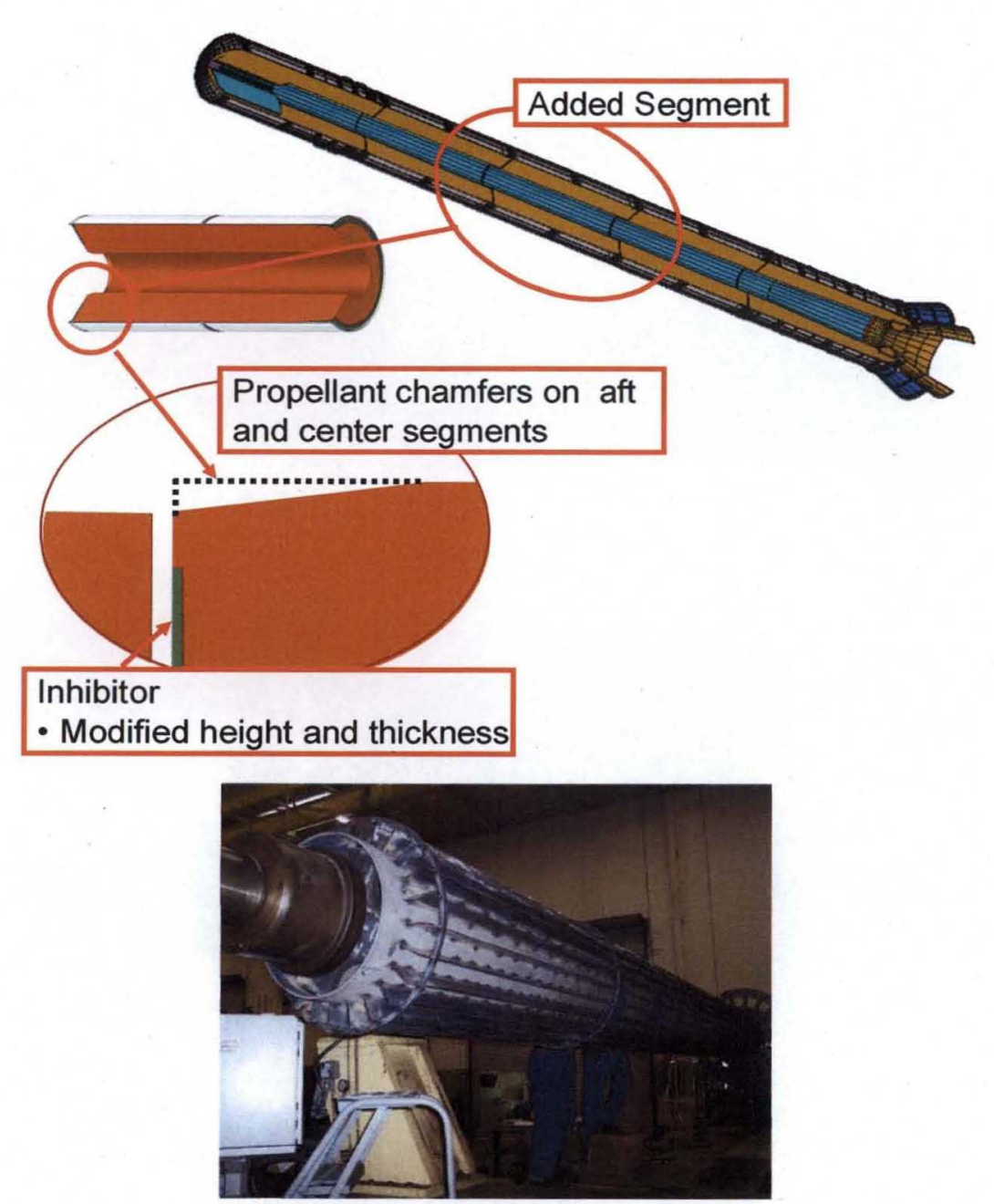

- Mandrel process simulators fabricated

- Modified propellant grain shape

- Chamfers prevent bore choking

- Vertical inhibitors added to ensure propellant burns evenly from axis

- Nozzle throat increased

- Aft exit cone extended

- Reformulated propellant to ensure ballistic thrust trace meets requirements 


\section{Avionics, Flight Termination System (FTS), and Pyro Shock Testing}

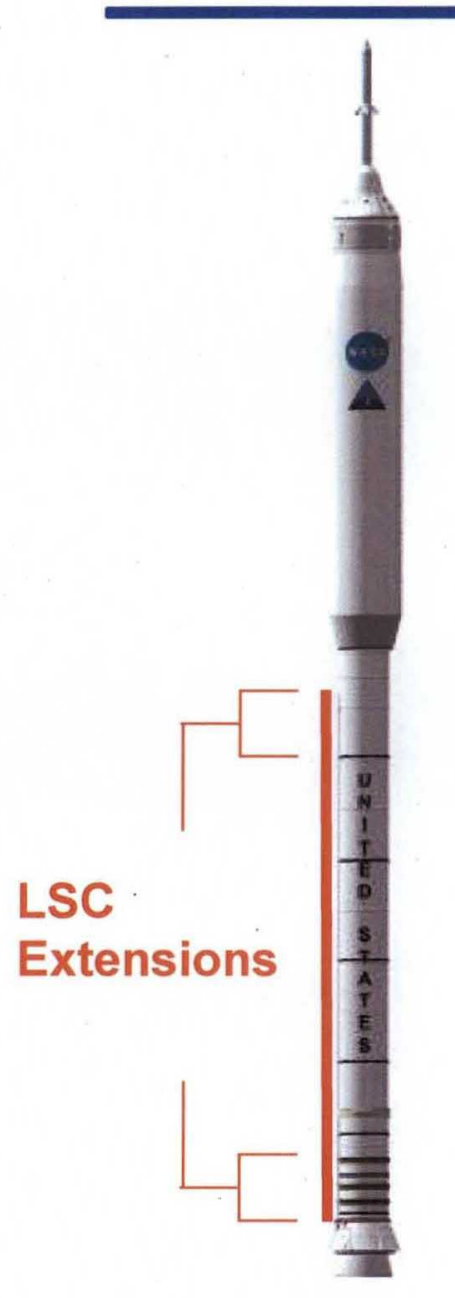

Avionics \& Controls

- Preliminary architecture defined

- Conducted assessment of the Thrust Vector Control (TVC) system's requirements

FTS

- Linear Shaped Charge (LSC) extended to fourth segment for Ares I-X-will reach all five segments on operational Ares I

Pyro Shock Testing

- Conducting pyro shock testing to characterize shock loads on avionics and thruster pressure cartridges

- Evaluating joint thickness, effective pyrotechnic mass per foot, and joint loadbearing capabilities 


\section{Parachute Testing}

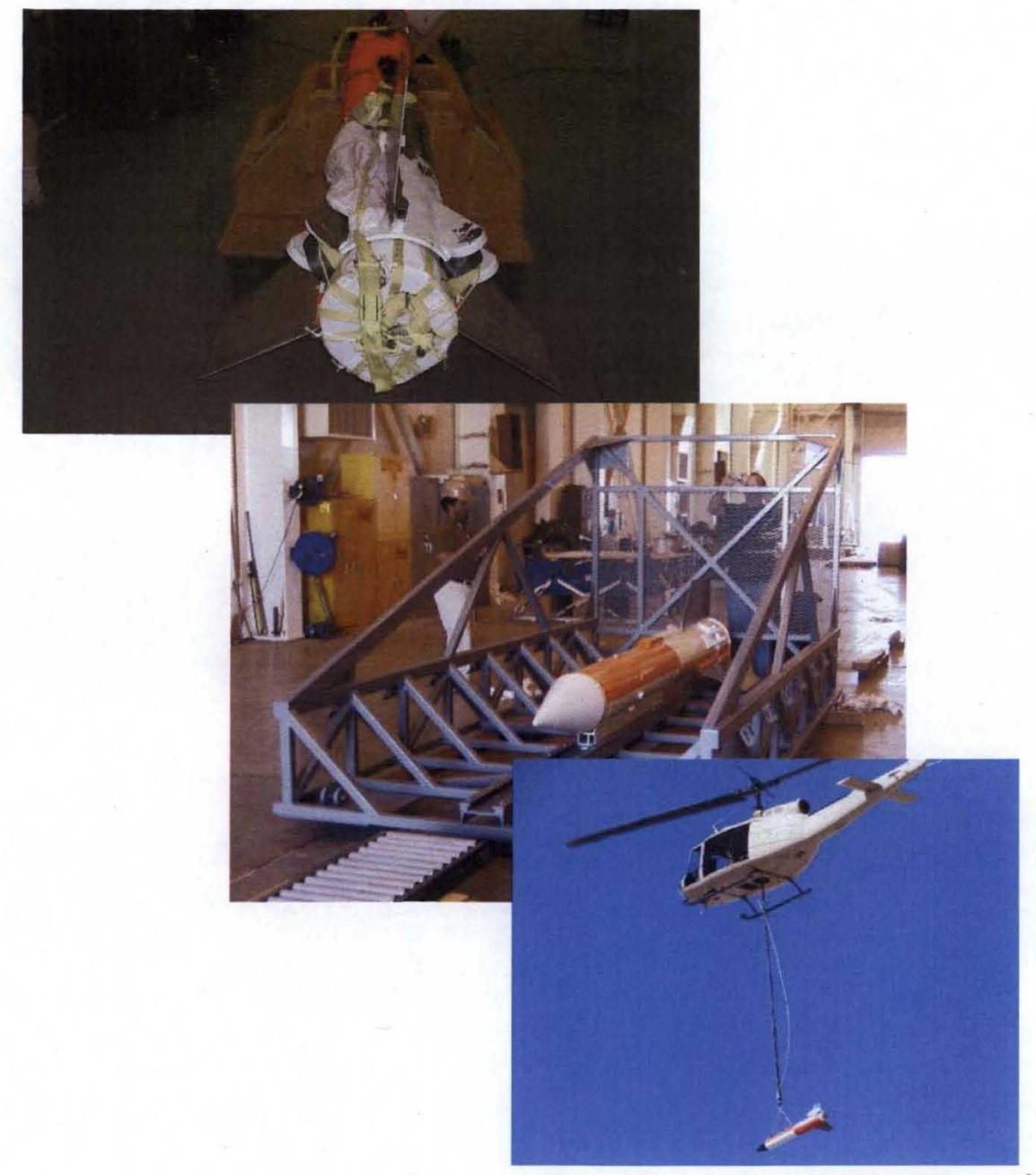

- Three sets of parachutes:

- Pilot

- Drogue

- Main

- Drop testing of pilot parachutes at Yuma Proving Grounds

- Two successful tests, one failure; more tests of pilot and drogue scheduled for later this year 


\section{Ares I-X Flight Test}

- New forward structures

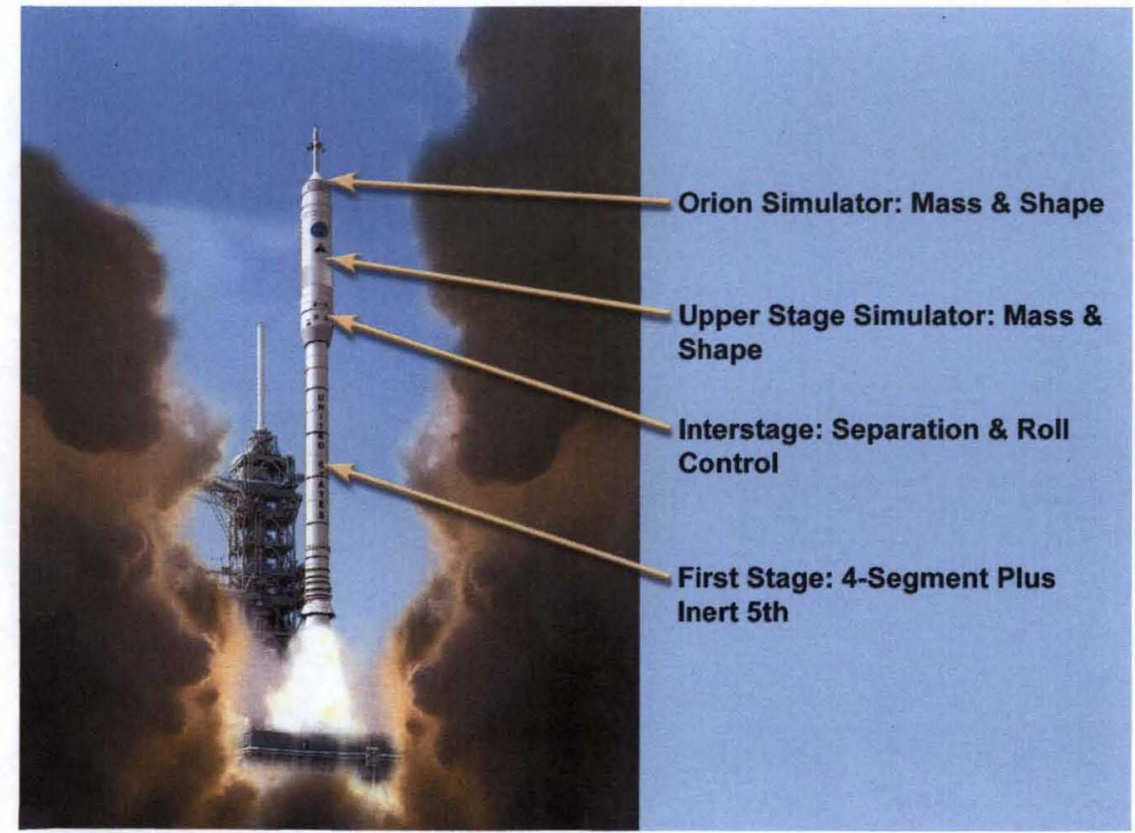
on "critical path" for test flight

- Test will mimic Ares I flight trajectory and separation environments as much as possible

- Booster to be recovered

- Evaluate reentry environments

- Retrieve data 


\section{Forward Work}

- Remaining two pilot parachute tests planned for the last week in July and one for late summer 2007

- The initial tests of the drogue and main parachutes scheduled to start in late 2007 and will finish in early 2009

- The avionics and control interfaces for the Ares I vehicle will be finalized by May 25

- Conducting a series of Ares I-X major design reviews (MDRs) for each of the sub-elements

- Pyro shock development tests will be performed on the heritage nosecap pressure cartridge in early June

- Participated in a vehicle-level PDR for the Ares I-X test flight at Langley Research Center (LaRC) during the first week of May. The results of that review will determine NASA's readiness to complete the design of the flight test vehicle, scheduled for April 2009. 


\section{Summary}

- Because the Ares I First Stage builds upon Space Shuttle legacy hardware, it has a head start on some of the other vehicle elements

- Critical efforts associated with developing the new avionics, forward structures, and motor modifications

- Using heritage hardware and improving known processes will ensure that Ares I remains a costeffective vehicle 


\section{Contact Information}

Tim Ezell

Tim.Ezell@nasa.gov

256-544-3620

\section{Questions?}

